\title{
Randomized Constraint Limit Linear Programming in Risk Management
}

\author{
Dennis Ridley1,2, Abdullah Khan ${ }^{3}$ \\ ${ }^{1}$ School of Business and Industry, Florida A \& M University, Tallahassee, FL, USA \\ ${ }^{2}$ Department of Scientific Computing, Florida State University, Tallahassee, FL, USA \\ ${ }^{3}$ School of Business, Claflin University, Orangeburg, SC, USA \\ Email: dridley@fsu.edu, akhan@claflin.edu
}

How to cite this paper: Ridley, D. and Khan, A. (2020) Randomized Constraint Limit Linear Programming in Risk Management. Journal of Applied Mathematics and Physics, 8, 2691-2702.

https://doi.org/10.4236/jamp.2020.811199

Received: October 16, 2020

Accepted: November 27, 2020

Published: November 30, 2020

Copyright (c) 2020 by author(s) and Scientific Research Publishing Inc. This work is licensed under the Creative Commons Attribution International License (CC BY 4.0).

http://creativecommons.org/licenses/by/4.0/

\begin{abstract}
Traditional linear program (LP) models are deterministic. The way that constraint limit uncertainty is handled is to compute the range of feasibility. After the optimal solution is obtained, typically by the simplex method, one considers the effect of varying each constraint limit, one at a time. This yields the range of feasibility within which the solution remains feasible. This sensitivity analysis is useful for helping the analyst get a feel for the problem. However, it is unrealistic because some constraint limits can vary randomly. These are typically constraint limits based on expected inventory. Inventory may fall short if there are overdue deliveries, unplanned machine failure, spoilage, etc. A realistic LP is created for simultaneously randomizing the constraint limits from any probability distribution. The corresponding distribution of objective function values is created. This distribution is examined directly for central tendencies, spread, skewness and extreme values for the purpose of risk analysis. The spreadsheet design presented is ideal for teaching Monte Carlo simulation and risk analysis to graduate students in business analytics with no specialized programming language requirement.
\end{abstract}

\section{Keywords}

Pedagogic Effectiveness of Big Data Analytics, Linear Programming, Stochastic Optimization, Constraint Limit, Profit Distribution and Risk, Monte Carlo Simulation

\section{Introduction}

\subsection{Risk Analysis and Business Analytics}

Risk analysis is an emerging topic in business management. The textbook 
"Business Analytics (Evans [1])" is designed to be spreadsheet (excel) based. It covers useful excel functions and illustrates how they are used to execute Monte Carlo simulation for the purpose of risk analysis. However, the chapter on linear optimization collapses to a traditional deterministic LP where the solution tool is the add-in SOLVER. Risk analysis in linear programming as described there relies on sensitivity analysis. In sensitivity analysis of the objective function, one objective function coefficient value at a time is varied within the range of optimality while all others are held constant. In the real world the coefficients can vary randomly and simultaneously. Ridley, et al. [2] describes a randomized linear program where all objective function coefficients are varied simultaneously. The random values are selected in accordance with any specified probability distribution. That paper and this one present spreadsheet designs for teaching Monte Carlo simulation and risk analysis to graduate students in business analytics (see also Stanton and Stanton [3]; Johnson, Albizri and Jain [4]; Pual and MacDonald [5]), with no requirement for a specialized programming language.

In sensitivity analysis of the constraint limits, one constraint value at a time is varied within the range of feasibility while all others are held constant. In the real world the constraint limits can vary randomly and simultaneously. This paper describes a randomized LP where all constraint limits are varied simultaneously. The random constraint limit values are selected in accordance with any specified probability distribution. Said distribution can be aligned with what occurs in reality. Some of these Monte Carlo simulations are feasible and some are not. The feasible solutions are kept, and the infeasible solutions are discarded and disregarded. The set of objective function values of the solutions that are kept represent the distribution of possible objective functions values. In the typical business problem, they are profits derived from random inventories, unplanned machine failure, spoilage, pilferage, etc. The analysis of these profits represents business risk analysis. It tells management the long term expected profit to plan for. It also tells the management the probability of low to no profits for which cash flow may be disrupted. If the expected profit is positive and acceptable, arrangement can be made to tide the business over during lean times.

The coefficients of the decision variables in the constraints of the LP are held constant throughout. They represent the rate at which the resources are consumed. They are technological coefficients. They cannot change randomly. They may change very slowly as new technological inventions occur and are implemented. But the time for this is well outside the planning horizon of the LP.

\subsection{Preparing Next Generation Business Analysts and Policy Planners}

According to Schoenherr et al. [6] the most needed skills for data scientists are forecasting, optimization, statistics, economics, mathematical modeling and applied probability. Modern world economies are arguably increasingly complex, more data enriched, technologically advanced, have gotten more predictable in 
some ways, yet are often impacted by uncertainties of various kinds across industries. Examples of such uncertainties include unpredictable fluctuations in demand, supply of outputs, raw materials, and supply chain stability and resilience. There are also the issues of scalability due to spatial or other constraints such as a pandemic etc. across various sectors (Tran and Smith [7]; Marino and Marufuzzaman [8]; Ivanov and Das [9]; Steen and Brandsen [10]). These uncertainties give rise to the need for research, teaching and learning of various stochastic optimization techniques. One important aspect of stochastic optimization is that it is inherently nonroutine in nature and hence does not lend itself readily to algorithms or automation. Due to the limitations in applying artificial intelligence to stochastic optimization, combined with increased uncertainties of various kinds in the natural and built environment, there is an increased need for training new generations of decision science practitioners who will have practical proficiency in stochastic programming. All these including the aforementioned diverse and contextual uncertainties trigger changes in constraints.

Mirkouei et al. [11] mentioned a four-step process-based framework that emphasizes engaging students of manufacturing engineering and allied disciplines in effective psychomotor learning for leveraging a participatory pedagogy. In the framework proposed there, the four steps suggested were as follows: define learning outcomes, create relevant and attractive instructional resources, create active learning resources, and develop a summative assessment mechanism. Researchers found positive benefits from using customized information technology equipment to promote student hands on learning. Suárez et al. [12] reported evidence that professors and students both found interactive Jupyter-notebook, an open-source web application, very effective for teaching and learning methods of optimization. Out of various canonical branches of stochastic optimization (Powell [13]), randomized constraint limit linear programming is an area that needs to be explored further. In order to groom a new generation of decision science practitioners as harbingers of the $4^{\text {th }}$ industrial revolution, we must teach students the skills of stochastic optimization. Students must learn to cope with and lead the waves of changes continually occurring in the economy and society (Gleason [14]). To meet the challenge, we must find innovative and more engaging ways to teach our decision science students variants of stochastic optimization techniques with the spirit of pedagogic flexibility and resilience.

\subsection{Organization}

The remainder of the paper is organized as follows. Section 2 is a review of related literature. Section 3 introduces the example problem used for illustration. The next section gives the traditional graphical solution. The next section gives the traditional algebraic solution and illustrates the new randomized LP solution. Some mathematical underpinnings are then explored. The final Section 4 summarizes some conclusions and suggestions for future research. 


\section{Literature Review}

LP as an optimization method can be traced back to the 1940s. Dantzig [15] was the pioneer of the simplex method for solving LP problems across various activities, sectors and industries including scientific research, for profit and not-for profit business operation management, infrastructure planning, spatial planning defense industry planning etc. The LP simplex method helps to solve optimization problems with specific objective functions (such as cost minimization, profit maximization, distance minimizing delivery routes planning, multi-plant production etc.) subject to input constraints of various forms. Although variant methods have been developed to solve large LP problems such as the interior point algorithm (Roos et al. [16]), construction of LP using aggregate data (Beliakov [17]), the issue of uncertainty in variables or coefficients in the objective function seem to have remained largely under-addressed.

LP is a deterministic global optimization method for finding a global maximum or minimum optimal solution subject to given constraints. One approach to deal with uncertainty is post optimality analysis, also known as sensitivity analysis (Higle and Wallace [18]). Sensitivity analysis is a "what if" scenario analysis where the effect on the optimal solution is measured against changing values for parameters. Several scholars (e.g. Eiselt et al. [19]; Hladík [20]; Panik [21]) discussed aspects of sensitivity analysis in greater detail.

Some degree of uncertainty is allowed under the fuzzy programming method where the desired objective value is assumed to be ambiguous (Bellman et al. [22]; Inuiguchi et al. [23]; Sakawa [24]). Another approach for dealing with uncertainty is Stochastic Programming (SP), as defined by Dantzig and Thapa [25] in a quest for deriving "the best plan of action (in some expected-value sense) while hedging against the myriad of possible ways the best laid plans can go awry". These stochastic methods utilize the expected values of the objective function coefficients when the coefficients are unknown during the decision-making processes.

Talluri et al. [26] exposited randomized linear program (RLP) for computing network bit prices, where itinerary demand realization sequences were simulated and solved using deterministic linear programming (DLP). They explained that RLP is only a little more complicated to implement than DLP. Wajs et al. [27] conducted risk analysis using DLP and applied Monte Carlo simulation modeling technique to explore greatest effects on the total remediation cost for a landfill area in a city in Poland contaminated from municipal solid waste disposal. Adler et al. [28] offered an extension of Clarkson's [29] randomized algorithm for a LP to a general scheme for finding solutions to convex optimization problems. The aim is to speed-up the simplex method (or any vertex enumeration method) for a LP when the number of constraints is much larger than the number of variables. Mohammed and Kassem [30] consider a product mix problem in which several scenarios are presented to examine the variant impacts on revenue, profit, materials cost, resources' utilization and productivity. However, 
these stochastic methods do not consider solutions for all values of the random coefficient.

Cai, et al. [31] employ an interval linear programming (ILP) method to derive optimum alternative solutions under multiple uncertainties related to energy sector management with the help of a fuzzy random interval programming model. They contend that solutions obtained will be helpful for more efficient enterprise resource planning (ERP) systems. The ERP systems basically provide support to various units of an enterprise (such as production, marketing, and sales) so that they can access, share and integrate necessary data simultaneously as required. $\mathrm{Wu}$ [32] proposed three experimental models of robustness under uncertainty regarding global supply chain management for manufacturing industries. Pourjavad and Mayorga [33] proposed a fuzzy multi-objective mixed-integer LP model which is at first transformed into multi-objective mixed integer LP by a weighted average method. Then, variants of fuzzy programming approaches are utilized to find solutions for a sustainable supply chain under uncertainty. However, the foregoing cited research papers do not create LP methods that allow for simultaneous randomization of the constraint limits from any probability distribution.

\section{The Linear Program}

The general LP may be written as

$$
\begin{array}{ll}
\text { Maximize } & p^{\mathrm{T}} x=z \\
\text { Subject to } & A x \leq b \\
& x \geq 0
\end{array}
$$

where $x=\left(x_{1}, x_{2}, x_{3}, \cdots, x_{n}\right)$ is a vector of decision variables, $p=\left(p_{1}, p_{2}, p_{3}, \cdots, p_{n}\right)$ is a vector of independent profit contributions, $b=\left(b_{1}, b_{2}, b_{3}, \cdots, b_{m}\right)$ is a vector of constraint limits, and $A$ is an $m \times n$ matrix of constants.

Consider an example taken from Evans [[1], p. 474]. The name of the business is Slenka Ski. Slenka Ski produces two types of Skis, Jordanelle and Deercrest. The per unit profit contributions are $\$ 50$ and $\$ 65$ respectively. There is a fabrication constraint of 84 hours and a finishing constraint of 21 hours. Jordanelle uses 3.5 hours of fabrication time and 1 hour of finishing time. Deercrest uses 4.0 hours of fabrication time and 1.5 hours of finishing time. There is also a market mix requirement that Deercrest production must be no less than twice that of Jordanelle. As always, there are the nonnegativity constraints.

Let Jordanelle be represented by $X_{1}$ and Deercrest be represented by $X_{2}$.

\section{SLACK SLOPE}

$$
\begin{array}{llllll}
\text { Maximize } & 50 X_{1}+65 X_{2} & & & & \\
\text { Subject to } & 3.5 X_{1}+4.0 X_{2} \leq 84 & 23.625 & -0.875 & & \text { (Fabrication) } \\
& 1.0 X_{1}+1.5 X_{2} \leq 21 & 0.0 & -0.667 & \text { Binding } & \text { (Finishing) } \\
& -2.0 X_{1}+1.0 X_{2} \geq 0 & 0.0 & 2.0 & \text { Binding } & \text { (Market mix) } \\
& X_{1}, X_{2} \geq 0 & & & & \text { (nonnegativity) }
\end{array}
$$


The deterministic graphical solution is given in Figure 1, where $X_{1}=5.25, X_{2}$ $=10.5$, and the Objective function value (profit) $=\$ 945$. The fractional amounts of $X_{1}$ and $X_{2}$ are interpreted as work in progress.

\section{Graphical Solution}

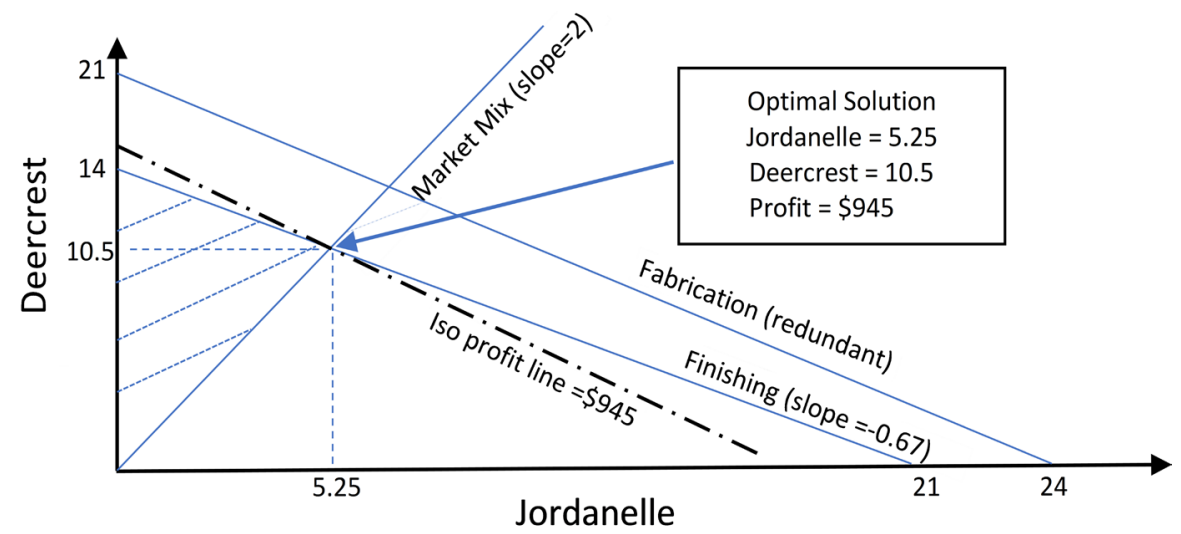

Figure 1. Graphical solution of a deterministic LP.

\section{Algebraic Solutions}

The first algebraic solution will be created in an excel spreadsheet and executed by the add-in SOLVER. A spreadsheet for the production of Slenka Skis is shown in Figure 2.

Deterministic solution

Rewriting the LP in terms of the excel fields, the problem formulation is

Maximize Profit $=$

$$
\begin{aligned}
& \mathrm{D} 22=\mathrm{B} 9 * \mathrm{~B} 14+\mathrm{C} 9 * \mathrm{C} 14 \\
& \mathrm{D} 15=\mathrm{B} 6 * \mathrm{~B} 14+\mathrm{C} 6 * \mathrm{C} 14 \leq \mathrm{D} 6 \\
& \mathrm{D} 16=\mathrm{B} 7 * \mathrm{~B} 14+\mathrm{C} 7 * \mathrm{C} 14 \leq \mathrm{D} 7 \\
& \mathrm{D} 19=\mathrm{B} 8 * \mathrm{~B} 14+\mathrm{C} 8 * \mathrm{C} 14 \geq \mathrm{D} 8
\end{aligned}
$$

Subject to

Initially, all parameters of the LP, including the objective function coefficients, are assumed to be known at the time that a decision is to be made regarding the optimal values of the decision variables. The original objective coefficients (not shown to save space) are 50 for Jordanelle and 65 for Deercrest. This LP was solved by the excel add-in SOLVER. The solution is $X_{1}=(\mathrm{B} 14=5.25)$, $X_{2}=(\mathrm{C} 14=10.5)$. The profit for this configuration is D22 = SUMPRODUCT $(\$ B \$ 9: \$ C \$ 9, \$ B \$ 14: \$ C \$ 14)=\$ 945$. See the LP in the top left corner of Figure 2.

\section{Monte Carlo Simulation}

The Monte Carlo simulations are based on 100 sets of two constraint limits. To save space 30 are shown in Figure 2. The fabrication constraint is assumed to be normally distributed with a mean of 84 hours and standard deviation of 1 hour. The finishing constraint is assumed to be normally distributed with a mean of 21 hours and a standard deviation of 1 hour. The simulations were repeated with standard deviations of 5 hours for both constraints. SOLVER is executed for each combination of constraint limits. In each case the profit is computed and saved. These profits are used to construct histograms of profit distributions. 


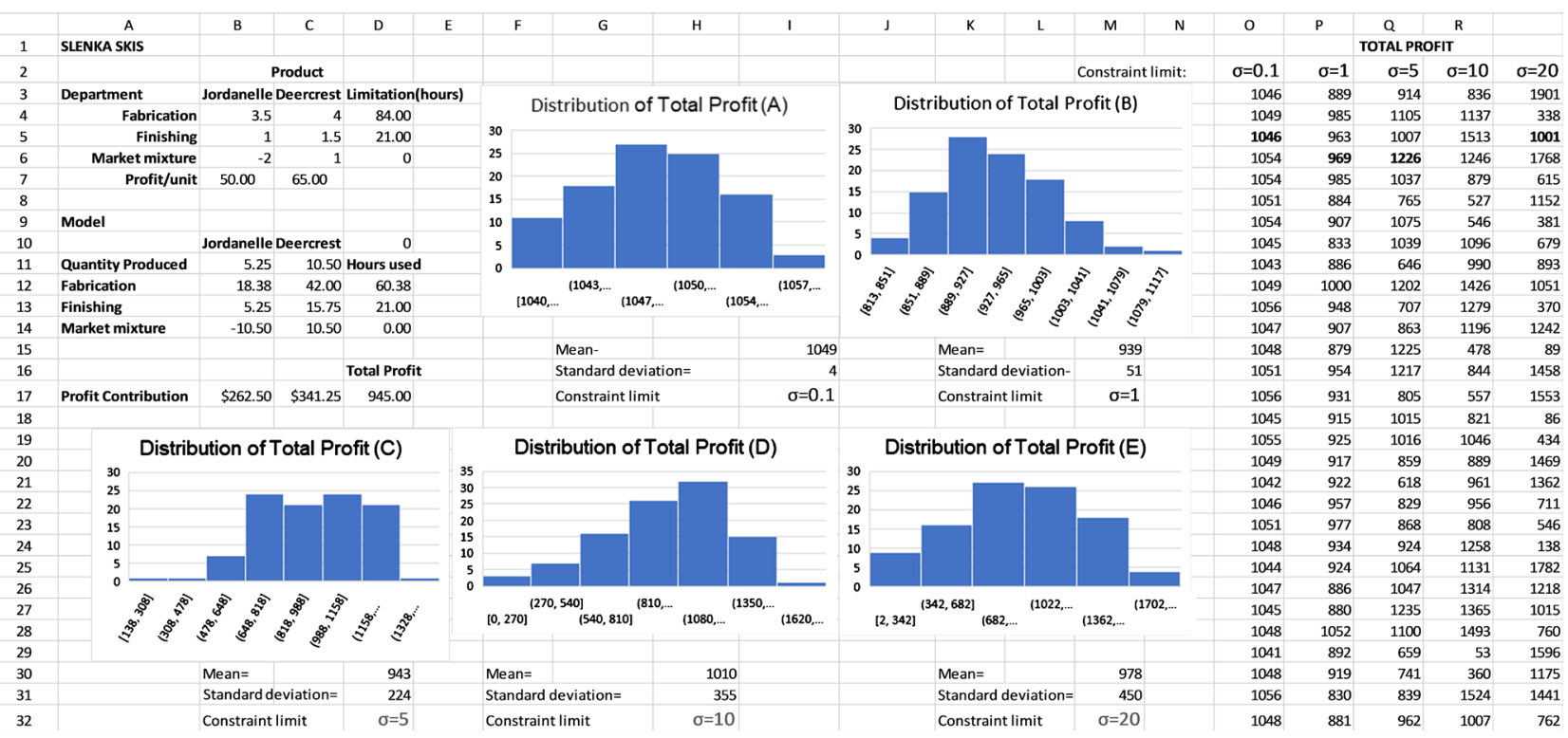

Figure 2. Monte Carlo computer simulations of LP profit for random constraint limits.

\section{Profit Distribution}

The profit distributions are given in Figure 2 for a fabrication time constraint limit that is normal with mean 84 hours and standard deviation 0.1 hour. The finishing time constraint limit is normal with mean 21 hours and standard deviation 0.1 hour. The resulting mean profit is $\$ 1049$ with a standard deviation of $\$ 4$ and the shape is similar to a normal distribution. The simulation is repeated with both constraint limit time standard deviations changed to 1 hour. The resulting mean profit is $\$ 939$ with a standard deviation of $\$ 51$ and the shape is right skewed, similar to a chi-square distribution.

\section{Mathematical Underpinning}

Let us consider the effect of the randomness in the constraint limits on profit. The constraints themselves are independent of each other. One constraint limit does not affect the other. But their effects can combine via the structure of the LP to impact the profit. Consider the possibility of a multiplicative combination. To investigate this possibility, consider $Y=X^{2}$, where $X>0$ is profit. Then, the cumulative distribution of $Y$ is

$$
F_{Y}(x)=P\left(X^{2}<x\right)=P(|X|<\sqrt{x})=P(-\sqrt{x}<X<\sqrt{x}),
$$

where $P$ denotes probability.

That is, $F_{Y}(x)=F_{X}(\sqrt{x})-F_{X}(-\sqrt{x})$.

Then, $f_{Y}(x)=F_{Y}^{\prime}(x)=\frac{1}{2 \sqrt{x}} f_{X}(\sqrt{x})+\frac{1}{2 \sqrt{x}} f_{X}(-\sqrt{x}), x>0$.

If $X \sim N(\mu, \sigma), \quad f_{X}(x)=\frac{1}{\sqrt{2 \pi} \sigma} \mathrm{e}^{-\frac{(x-\mu)^{2}}{2 \sigma^{2}}}$

Then, $f_{Y}(x)=\frac{1}{2 \sqrt{x}} \frac{1}{\sqrt{2 \pi} \sigma} \mathrm{e}^{-\frac{(\sqrt{x}-\mu)^{2}}{2 \sigma^{2}}}+\frac{1}{2 \sqrt{x}} \frac{1}{\sqrt{2 \pi} \sigma} \mathrm{e}^{-\frac{(-\sqrt{x}-\mu)^{2}}{2 \sigma^{2}}}, x>0$. 
And, if $X \sim N(0,1)$ then

$$
\begin{gathered}
f_{Y}(x)=\frac{1}{2 \sqrt{x}} \frac{1}{\sqrt{2 \pi}} \mathrm{e}^{-x / 2}+\frac{1}{2 \sqrt{x}} \frac{1}{\sqrt{2 \pi}} \mathrm{e}^{-x / 2}, x>0, \\
f_{Y}(x)=\frac{1}{\sqrt{2 \pi x}} \mathrm{e}^{-x / 2}, x>0 .
\end{gathered}
$$

Therefore, $X^{2}$ follows a chi-square $\left(\chi^{2}\right)$ distribution with 1 degree of freedom.

As it turns out, examination of the profit histogram for $\sigma=1$ hour shows that it bears resemblance to the theoretical $\chi^{2}$ distribution. Also, it is well known that as the ratio of the mean to the standard deviation $(\mu / \sigma)$ increases, the $\chi^{2}$ distribution approaches a normal distribution. As it turns out, the profit histogram for the smaller $\sigma=0.1$ hour bears resemblance to the theoretical normal distribution. In either case, high profit is unlikely to be a source of business concern. So, the amount of spread represented in the histograms is an indicator of risk of low profit, albeit temporary. These are consistent with the above formulated normal/chi-square relationship. In the long run, low profit periods will be offset by high profit periods. This implies that the simple solution to guard against problems of cash flow is to arrange a bank overdraft protection plan.

Continuing on in this investigation, consider the profit distributions when the constraint limit standard deviation is increased to $\sigma=5$ hours. The resulting mean profit is \$ 943 with a standard deviation of \$ 224 and the shape is similar to a uniform distribution. The distribution is flattening. As the standard deviation is increased to $\sigma=10$ hours, the mean profit is $\$ 1010$ with a standard deviation of $\$ 335$ and the shape is skewed to the left. As the standard deviation is increased to $\sigma=20$ hours, the mean profit is $\$ 978$ with a standard deviation of $\$ 450$ and the shape once more appears normal. In retrospect, after reviewing all five histograms (A-E), they appear to follow a skew generalized normal distribution. Skew generalized normal here means extension of skew normal (O’Hagan and Leonard [34]; Ashour and Abdel-hameed [35]; Azzalini [36]). The distribution includes a shape parameter (Hosking and Wallis [37]), that determines the amount and direction of skew. To obtain these results, the shape parameter must be a function of the standard deviation. Positive shape for left skew, negative shape for right skew and zero shape for symmetric normality. Segment (A) appears normal. Segment (B) is right skewed. Segment (C) appears uniform and contains a point of inflection as the skew goes from right to left. This uniform segment bears resemblance to the special extreme platykurtic case of the generalized normal distribution when the top is flat (Figure 4). Segment (D) is left skewed. Segment (E) appears normal. The distributions (A-E) appear to be five from a family of distributions comprising a skew generalized normal distribution.

This family is depicted in the theoretical skew generalize normal distributions in Figure 3. The probability density function (PDF) is 


$$
\frac{\varphi(y)}{\alpha-\kappa(x-\xi)}
$$

where

$$
y= \begin{cases}-\frac{1}{\kappa} \log \left[1-\frac{\kappa(x-\xi)}{\alpha}\right] & \text { if } \kappa \neq 0 \\ \frac{x-\xi}{\alpha} & \text { if } \kappa=0\end{cases}
$$

and $\varphi$ is the standard normal PDF $(1 / \sqrt{2 \pi}) \mathrm{e}^{-y^{2} / 2}$.

The cumulative density function (CDF) is $\Phi(y)$ where $\Phi$ is the standard normal $\mathrm{CDF}, \xi$ represents location (real), $\alpha$ represents scale (positive, real) and $\kappa$ represents shape (real). The symmetric center segment in Figure 3 $(\kappa=0)$ is further designed per the special case of the uniform flat top distribution from the generalized normal distribution in Figure $4(\beta=8)$.

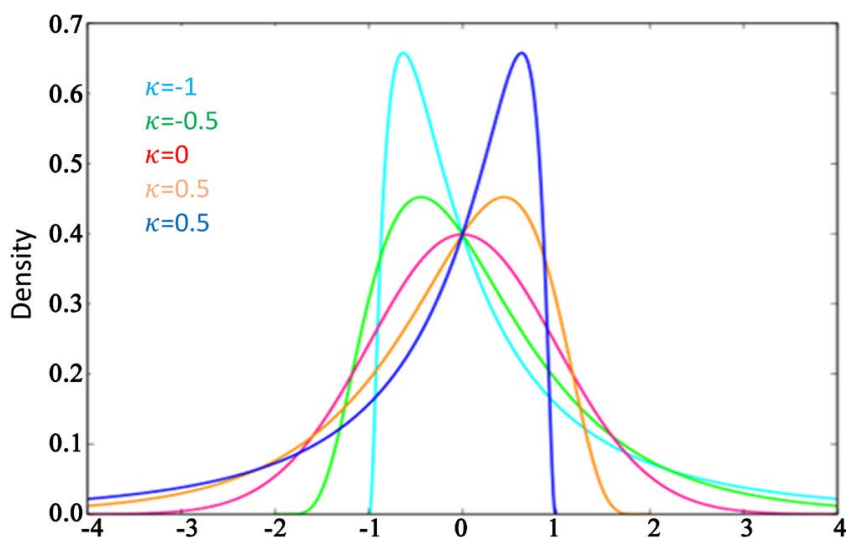

Figure 3. Skew generalized normal distribution.

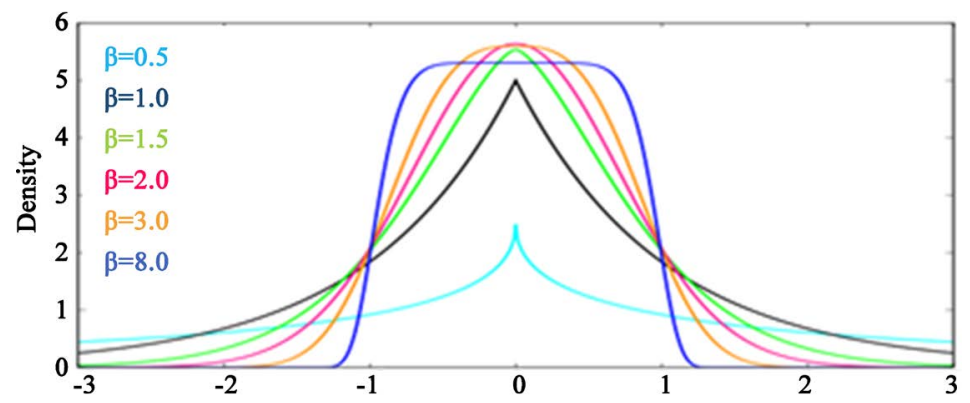

Figure 4. Generalized normal distribution.

The generalized normal distribution is shown in Figure 4. The PDF is $(\beta / 2 \alpha \Gamma(1 / \beta)) \mathrm{e}^{-(|x-\mu| / \alpha)^{\beta}}$, where $\mu$ represents location (real), $\alpha$ represents scale (positive, real), $\beta$ represents shape (positive, real) and $\Gamma$ denotes the Gamma function.

\section{Conclusion}

Randomized constraint limits are more realistic than deterministic limits assumed 
to be known ahead of time. Numerous contingencies can result in changes in production limitations. For the case of normally distributed LP constraint limits, the simulated profits follow what appears to be a skew generalized normal distribution that approaches a normal distribution. When the variance is small or large the distribution is bell shaped. In between these, the shape is flat topped, a special case of the generalized normal distribution. Risk can be managed by arranging a bank overdraft plan that compensates for the risk implied by the profit distribution. The results of this research are quite a fascinating and unexpected outcome. Instructional one might say. The spreadsheet design for randomizing and solving the LP constraint limits expands the use of excel in teaching Monte Carlo simulation and risk analysis to graduate students in business analytics with no specialized programming language required. In this paper the excel add-in SOLVER is user executed for each combination of constraint limits. One might investigate the creation of an embedded VB script to automate the execution of SOLVER and may incorporate the same functionality in Jupyter-notebook. Future research might consider other constraint limit distributions.

\section{Conflicts of Interest}

The authors declare no conflicts of interest regarding the publication of this paper.

\section{References}

[1] Evans, J.R. (2020) Business Analytics. 3rd Edition, Pearson, New Jersey.

[2] Ridley, A.D., Laugell, F., Daniels, I. and Khan, A. (2020) Randomized Objective Function Linear Programming in Risk Management. (Forthcoming)

[3] Stanton, W.W. and Stanton, A.D. (2020) Helping Business Students Acquire the Skills Needed for a Career in Analytics: A Comprehensive Industry Assessment of Entry-Level Requirements. Decision Sciences Journal of Innovative Education, 18, 138-165. https://doi.org/10.1111/dsji.12199

[4] Johnson, M.E., Albizri, A. and Jain, R. (2020) Exploratory Analysis to Identify Concepts, Skills, Knowledge, and Tools to Educate Business Analytics Practitioners. Decision Sciences Journal of Innovative Education, 18, 90-118. https://doi.org/10.1111/dsji.12195

[5] Pual, A. and MacDonald, L. (2020) Analytics Curriculum for Undergraduate and Graduate Students. Decision Sciences Journal of Innovative Education, 18, 22-58. https://doi.org/10.1111/dsji.12196

[6] Schoenherr, T. and Speier-Pero, C. (2015) Data Science, Predictive Analytics, and Big Data in Supply Chain Management: Current State and Future Potential. Journal of Business Logistics, 36, 120-132. https://doi.org/10.1111/jbl.12082

[7] Tran, T.T. and Smith, A.D. (2017) Evaluation of Renewable Energy Technologies and Their Potential for Technical Integration and Cost-Effective Use within the US Energy Sector. Renewable and Sustainable Energy Reviews, 80, 1372-1388. https://doi.org/10.1016/j.rser.2017.05.228

[8] Marino, C.A. and Marufuzzaman, M. (2020) A Microgrid Energy Management System Based on Chance-Constrained Stochastic Optimization and Big Data Analytics. Computers \& Industrial Engineering, 143, 106392. 
https://doi.org/10.1016/j.cie.2020.106392

[9] Ivanov, D. and Das, A. (2020) Coronavirus (COVID-19/SARS-CoV-2) and Supply Chain Resilience: A Research Note. International Journal of Integrated Supply Management, 13, 90-102. https://doi.org/10.1504/IJISM.2020.107780

[10] Steen, T. and Brandsen, T. (2020) Co-Production during and after the COVID-19 Pandemic: Will It Last? Public Administration Review, 80, No. 5. https://doi.org/10.1111/puar.13258

[11] Mirkouei, A., Bhinge, R., McCoy, C., Haapala, K.R. and Dornfeld, D.A. (2016) A Pedagogical Module Framework to Improve Scaffolded Active Learning in Manufacturing Engineering Education. Procedia Manufacturing, 5, 1128-1142. https://doi.org/10.1016/j.promfg.2016.08.088

[12] Suárez, A., Alvarez-Feijoo, M.A., Fernández González, R. and Arce, E. (2018). Teaching Optimization of Manufacturing Problems via Code Components of a Jupyter Notebook. Computer Applications in Engineering Education, 26, 1102-1110. https://doi.org/10.1002/cae.21941

[13] Powell, W.B. (2019) A Unified Framework for Stochastic Optimization. European Journal of Operational Research, 275, 795-821.

https://doi.org/10.1016/j.ejor.2018.07.014

[14] Gleason, N.W. (2018) Higher Education in the Era of the Fourth Industrial Revolution. Springer Nature, 229. https://doi.org/10.1007/978-981-13-0194-0

[15] Dantzig, G.B. (1951) Application of the Simplex Method to a Transportation Problem. In: Koopmans, T.C., Ed., Activity Analysis of Production and Allocation, Wiley, New York, 359-373.

[16] Roos, C. Terlaky, T. and Vial J-Ph. (2006) Interior Point Methods for Linear Optimization. 2nd Edition, Springer, New York.

[17] Beliakov, G. (2009) Construction of Aggregation Functions from Data Using Linear Programming. Fuzzy Sets and Systems, 160, 65-75.

[18] Higle, J.L. and Wallace, S.W. (2003) Sensitivity Analysis and Uncertainty in Linear Programming. Interfaces, 33, 53-60. https://doi.org/10.1287/inte.33.4.53.16370

[19] Eiselt, H.A. and Sandblom, C.L. (2007) Linear Programming and Its Applications. Springer-Verlag, Berlin, Heidelberg.

[20] Hladík, M. (2010) Generalized Linear Fractional Programming under Interval Uncertainty. European Journal of Operational Research, 205, 42-46. https://doi.org/10.1016/j.ejor.2010.01.018

[21] Panik, M. (2019) Linear Programming and Resource Allocation Modeling. John Wiley \& Sons, Inc., Hoboken.

[22] Bellman, R.E. and Zadeh, L.A. (1970) Decision-Making in a Fuzzy Environment. Management Science, 17, 141-164. https://doi.org/10.1287/mnsc.17.4.B141

[23] Inuiguchi, M. and Ramík, J. (2000) Possibilistic Linear Programming: A Brief Review of Fuzzy Mathematical Programming and a Comparison with Stochastic Programming in Portfolio Selection Problem. Fuzzy Sets and Systems, 111, 3-28. https://doi.org/10.1016/S0165-0114(98)00449-7

[24] Sakawa M. (2002) Fuzzy Multiobjective and Multilevel Optimization. In: Ehrgott, M. and Gandibleux, X., Eds., Multiple Criteria Optimization: State of the Art Annotated Bibliographic Survey, Kluwer, The Netherlands, 171-226. https://doi.org/10.1007/0-306-48107-3 4

[25] Dantzig, G.B. and Thapa, M.N. (2003) Linear Programming 2: Theory and Extensions. Springer-Verlag, New York. 
[26] Talluri, K. and Van Ryzin, G. (1999) A Randomized Linear Programming Method for Computing Network Bid Prices. Transportation Science, 33, 207-216.

https://www0.gsb.columbia.edu/mygsb/faculty/research/pubfiles/3929/programmin g\%20method.pdf https://doi.org/10.1287/trsc.33.2.207

[27] Wajs, W., Bieda, B. and Tadeusiewicz, R. (2001). Linear Programming and Risk Analysis Methods for Municipal Solid Waste Decision Support System. IFAC Proceedings Volumes, 34, 187-192. https://doi.org/10.1016/S1474-6670(17)33204-4

[28] Adler, I. and Shamir, R. (1993) A Randomized Scheme for Speeding up Algorithms for Linear and Convex Programming Problems with High Constraints-to-Variables Ratio. Mathematical Programming, 61, 39-52. https://doi.org/10.1007/BF01582137

[29] Clarkson, K.L. (1988) A Las Vegas Algorithm for Linear Programming When the Dimension Is Small. Proceedings of the 29th IEEE Symposium on the Foundations of Computer Science, White Plains, 24-26 October 1988.

https://doi.org/10.1109/SFCS.1988.21961

[30] Mohammed, A.R. and Kassem, S.S. (2020) Product Mix Optimization Scenarios: A Case Study for Decision Support Using Linear Programming Approach. International Conference on Innovative Trends in Communication and Computer Engineering (ITCE), Aswan, 8-9 February 2020, 50-55. https://doi.org/10.1109/ITCE48509.2020.9047758

[31] Cai, Y.P., Huang, G.H., Yang, Z.F. and Tan, Q. (2009) Identification of Optimal Strategies for Energy Management Systems Planning under Multiple Uncertainties. Applied Energy, 86, 480-495. https://doi.org/10.1016/j.apenergy.2008.09.025

[32] Wu, Y. (2006) Robust Optimization Applied to Uncertain Production Loading Problems with Import Quota Limits under the Global Supply Chain Management Environment. International Journal of Production Research, 44, 849-882. https://doi.org/10.1080/00207540500285040

[33] Pourjavad, E. and Mayorga, R.V. (2019) A Comparative Study on Fuzzy Programming Approaches to Design a Sustainable Supply Chain under Uncertainty. Journal of Intelligent \& Fuzzy Systems, 36, 2947-2961. https://doi.org/10.3233/JIFS-171168

[34] O’Hagan, A. and Leonard, T. (1976) Bayes Estimation Subject to Uncertainty about Parameter Constraints. Biometrika, 63, 201-203.

https://doi.org/10.1093/biomet/63.1.201

[35] Ashour, K. and Abdel-hameed, A. (2010) Approximate Skew Normal Distribution. Journal of Advanced Research, 1, 341-350. https://doi.org/10.1016/j.jare.2010.06.004

[36] Azzalini, A. (1985) A Class of Distributions Which Includes the Normal Ones. Scandinavian Journal of Statistics, 12, 171-178.

[37] Hosking, J.R.M. and Wallis, J.R. (1997) Regional Frequency Analysis: An Approach Based on L-Moments. Cambridge University Press, Cambridge, Section A.8. https://doi.org/10.1017/CBO9780511529443 